(c) American Dairy Science Association, 2002.

\title{
Molecular Typing of Streptococcus uberis Strains Isolated from Cases of Bovine Mastitis
}

\author{
R. J. Wieliczko, ${ }^{\star}$ J. H. Williamson,† R. T. Cursons, ${ }^{*}$ \\ S. J. Lacy-Hulbert, $\dagger$ and M. W. Woolford $\dagger$ \\ *Department of Biological Science, \\ University of Waikato, Private Bag 3105 \\ Hamilton, New Zealand \\ †Dexcel Limited, \\ Private Bag 3221 \\ Hamilton, New Zealand
}

\section{ABSTRACT}

The discriminatory power of two polymerase chain reaction-based DNA fingerprinting methods, random amplified polymorphic DNA and repetitive extragenic palindrome were compared by subtyping 128 isolates of Streptococcus uberis cultured from cows in six different dairy herds in New Zealand. The typing results demonstrated that the majority of isolates possessed unique fingerprint profiles except on occasions where multiple isolates were obtained from individual cows. On these occasions, individual quarters of the mammary gland were generally, but not exclusively, infected by the same strain of bacteria. Both random amplified polymorphic DNA and repetitive extragenic palindromic typing assays were simple to perform, relatively inexpensive ( $\$ 11.00$ per reaction), and provided reliable and reproducible results. Furthermore, when these assays were used in conjunction with each other, they provided a means of confirmation of the specific DNA fingerprint patterns obtained.

(Key words: molecular typing, Streptococcus uberis, mastitis)

Abbreviation key: PFGE = pulsed-field gel electrophoresis, $\mathbf{R A P D}=$ random amplified polymorphic DNA, $\mathbf{R E P}=$ repetitive extragenic palindromic.

\section{INTRODUCTION}

Streptococcus uberis continues to be a major cause of bovine mastitis, particularly in rotationally grazed pastoral systems such as in New Zealand (Brookbanks, 1966; McDougall, 1998). Much of the new IMI occurs around calving (Pankey et al., 1982; Williamson et al.,

Received June 7, 2001.

Accepted May 30, 2002

Corresponding author: R. Cursons; e-mail: r.cursons@ waikato.ac.nz.
1995) and first calf heifers are particularly at risk of new infections (Pankey et al., 1996). The risk of Strep. uberis IMI also remains high in the early dry period, especially in herds that do not use dry cow treatments prophylactically (Williamson et al., 1995). Besides the immediate impact of mastitis on milk production, health, and welfare, mastitis also has a significant effect on the economics of the wider dairy industry (Holdaway, 1990).

Routine hygiene procedures at milking time do not appear to be as effective in preventing new infections by Strep. uberis. It is assumed that teats become colonized by Strep. uberis located in the cow's environment and colonization subsequently predisposes the cow to infection. Subtyping of bacteria can contribute to the epidemiological understanding of such infections by recognizing particular strains of bacteria associated with an outbreak, by detection of any cross-transmission associated with an outbreak, by recognizing significant virulent strains, and by identifying any reinfections (Olive and Bean, 1999).

A number of DNA fingerprinting methods for the subtyping of Strep. uberis have been published. These include restriction endonuclease fingerprinting (Hill and Leigh, 1989) random amplified polymorphic DNA (RAPD) (Gillespie et al., 1997; Gillespie et al., 1998) and pulsed-field gel electrophoresis (PFGE) techniques (Baseggio et al., 1997; Wang et al., 1999; Douglas et al., 2000). Any subtyping method must have a high power to differentiate between unrelated strains (discriminatory power) and be reproducible (i.e., the ability to obtain identical results for repeated analyses of the same strain) in order to develop a reliable database. Of all the molecular typing methods available, RAPD and repetitive extragenic palindromic (REP)-PCR methods are the easiest to implement. Both methods also possess advantages compared with PFGE including speed and low relative cost (Olive and Bean, 1999).

The object of this study was to evaluate the use of RAPD for typing 128 New Zealand bovine isolates of 
Strep. uberis and to evaluate its use in comparison to REP typing.

\section{MATERIALS AND METHODS}

\section{Bacterial Isolates}

A total of 128 Strep. uberis isolates from 113 cows obtained from the bovine mammary gland were used in this study. Isolates were obtained from six different dairy herds in the Waikato region by Dexcel, Ltd. (formerly Dairying Research Corporation, Ltd.), Hamilton, New Zealand, and were a combination of isolates from clinical mastitis cases and persistent subclinical IMI. Clinical mastitis was defined as any visible abnormalities in the milk, which was sometimes associated with pain and swelling in the gland. An additional four reference strains of Strep. uberis were obtained from the United Kingdom by Dexcel, Ltd.

Foremilk samples for culture were collected using standard aseptic technique by trained field technicians. Primary culture was on $0.1 \%$ esculin blood agar, with isolates being presumptively selected for molecular fingerprinting on the basis of colony morphology, Gram stain, catalase reaction, and esculin hydrolysis. Isolates were further identified as Strep. uberis by polymerase chain reaction of the 16S-23S rRNA spacer region (Forsman et al., 1997).

\section{Isolation of DNA}

Chromosomal DNA of Strep. uberis was isolated using the following protocol: An overnight culture of bacteria grown on brain-heart infusion agar was resuspended in $0.5 \mathrm{ml}$ of sterile TE buffer $(10 \mathrm{~m} M$ Tris $\mathrm{pH} 8.0$; $1 \mathrm{~m} M$ EDTA). The culture was centrifuged at $13,000 \times$ $g$ for $10 \mathrm{~min}$, resuspended in $1.0 \mathrm{ml}$ of acetone, and incubated on ice for $5 \mathrm{~min}$, before pelleting the cells at $16,000 \times g$ for $5 \mathrm{~min}$. Acetone was removed and the pellet of bacteria dried at $56^{\circ} \mathrm{C}$ for $5 \mathrm{~min}$. Bacteria were then resuspended in $100 \mu \mathrm{l}$ of lysozyme solution $(50 \mathrm{mg} /$ $\mathrm{ml}$ in TE buffer) (Roche Diagnostics Corp., Indianapolis, IN) and incubated at $37^{\circ} \mathrm{C}$ for $1 \mathrm{~h}$. Following addition of $300 \mu \mathrm{l}$ of lysis solution (1.0\% SDS; $0.05 M$ EDTA; 0.1 $M$ Tris $\mathrm{pH} 9 ; 0.1 \mathrm{M} \mathrm{NaCl}$ ), the solution was incubated at $65^{\circ} \mathrm{C}$ for $1 \mathrm{~h}$. This was followed by addition of 300 $\mu \mathrm{l} 5 \mathrm{M} \mathrm{LiCl}$ and $750 \mu \mathrm{l}$ chloroform and the biphasic solution was rotated for $30 \mathrm{~min}$. Centrifugation was performed at $10,000 \times g$ for $10 \mathrm{~min}$, and the aqueous phase was collected and subjected to precipitation with an equal volume of isopropanol. The DNA was pelleted at $16,000 \times g$ for $20 \mathrm{~min}$, washed with $1.0 \mathrm{ml}$ of $70 \%$ ethanol, resuspended in $200 \mu \mathrm{l}$ of TE buffer, and stored at $4^{\circ} \mathrm{C}$.

\section{Primers}

Oligonucleotide primers were synthesized by SigmaAldrich Pty, Ltd., Castle Hill, Australia. Codes and sequences from $5^{\prime}$ to $3^{\prime}$ for these primers were as follow: Ope-4 (GTGACATGCC), P1 (GAGGGTGGCGGTTCT), Rep-2 (RCGYCTTATCMGGCCTAC) and Repir-dt (IIINCGNCGNCATCNGGC). The concentration of primers used per $50 \mu \mathrm{l}$ of reaction were: $0.56 \mu M$ for primer Ope-4, $0.42 \mu M$ for P1, $0.46 \mu M$ for Rep-2, and $0.44 \mu M$ for primer Repir-dt. Annealing temperatures were $33^{\circ} \mathrm{C}$ for primer Ope- 4 , and $45^{\circ} \mathrm{C}$ when $\mathrm{P} 1$ and REP primers were used.

\section{Polymerase Chain Reaction Amplification}

DNA amplification was performed in a total volume of $50 \mu \mathrm{l}$ containing $42 \mu \mathrm{l}$ of PCR Master Mix $10 \mathrm{mM}$ Tris pH 8.3; $2.5 \mathrm{mM} ; \mathrm{MgCl}_{2} ; 50 \mathrm{~m} M \mathrm{KCl}$ (Applied Biosystems, Foster City, CA); $250 \mu M$ deoxynucleotide triphosphates, $1 \mu \mathrm{l}$ of oligonucleotide primer, 3.0 U of Taq DNA polymerase (all from Roche Diagnostics), and 5 $\mu \mathrm{l}(0.125 \mu \mathrm{g})$ of genomic DNA. Each reaction mixture was overlaid with a wax bead and run for 40 cycles in a PTC-100 Programmable Thermal Controller (MJ Research, Inc., Watertown, MA). Following an initial denaturation step at $94.0^{\circ} \mathrm{C}$ for $2 \mathrm{~min}$, cycling parameters were set at $94.0^{\circ} \mathrm{C}$ for $30 \mathrm{~s} ; 33^{\circ} \mathrm{C}$ for $30 \mathrm{~s}$ with Ope4 , and $45^{\circ} \mathrm{C}$ for $30 \mathrm{~s}$ with $\mathrm{P} 1$ and Rep primers, followed by $72.0^{\circ} \mathrm{C}$ for $2 \mathrm{~min}$ (Gallego and Martinez, 1997). Ramp times were at $0.5^{\circ} \mathrm{C} / \mathrm{s}$.

For primers Ope- 4 and P1, $10 \times$ PCR Gold buffer (Perkin Elmer Biosystems, Norwalk, CT) was used. For primers Rep-2 and Repir-dt, 10xPCR buffer II (Perkin Elmer Biosystems) was used.

\section{Agarose Gel Electrophoresis}

Amplified products were electrophoresed in 2\% agarose using TBE buffer at $125 \mathrm{~V} / \mathrm{cm}$ for $55 \mathrm{~min}$. Gels were stained with ethidium bromide $(0.5 \mu \mathrm{g} / \mathrm{ml})$ and DNA was visualized by UV transillumination $(312 \mathrm{~nm})$ and photographed with a COHU High Performance CCD Camera. Band sizes were determined by comparison to a 100-bp DNA ladder (New England, BioLabs Inc.). Photographs were recorded with a Sony Digital Graphic Printer UP-D890.

\section{Analysis of Amplified DNA Fragments}

The complete gel was recorded and scanned into a matrix of densitometric values. The bitmap of digitized optical density values was transferred and stored as an image file of tagged image file format. All DNA patterns were analyzed with GelCompar software (version 4.1; 
Applied Maths; Kortrijk, Belgium). Degrees of homology were determined by Dice similarity coefficient and clustered using the Ward clustering algorithm (GelCompar, Reference Manual). Band position tolerance of $1.0 \%$ was used for comparison of the DNA patterns. Analysis of patterns was undertaken in accordance with manufacturer instructions.

DNA fingerprinting profiles were interpreted according to the total number of amplification products. If two or more isolates had an identical fingerprinting pattern, then the difference in band number was zero. However, profiles with the same number of bands were considered different if the sizes of the bands differed from each other. Indistinguishable strains, i.e., the same number and the same sizes of bands with similarity equal to $100.0 \%$ were considered genetically identical organisms in terms of determining identical not similar strains. Any relationship below $100.0 \%$ was recognized as closely related strains and exhibited similarities higher than $97.0 \%$. Possibly related strains were found below the range of $97.0 \%$ of similarity.

\section{RESULTS}

The interpretation of chromosomal DNA patterns is usually based on the divergence of these patterns from a selected type strain. Figure 1 compares the fingerprint profiles of four reference strains. The chromosomal DNA pattern of each individual reference strain differed from each other independent of primers used. The UK strain $0140 \mathrm{~J}$ was arbitrarily selected to be the type strain for further studies.

The initial profiles obtained at annealing temperatures of 33 to $45^{\circ} \mathrm{C}$, demonstrated that RAPD typing using Ope-4, P1 and REP typing exhibited optimal profiles at a specific annealing temperature of $33^{\circ} \mathrm{C}$ for Ope -4 and $45^{\circ} \mathrm{C}$ for P1 and REP. The quantity of template DNA was also very important in contributing to the reproducibility of the fingerprints.

The pattern of bands (i.e., the fingerprint profile observed on a typical agarose gel) could be divided into three classes of bands for each of the three primers:

1) Bands shared by all of the strains, signature bands;

2) Bands shared by many strains, common bands; and

3) Bands associated with individual strains, straincharacteristic bands.

Those bands with the most DNA base pairs migrated slowest through the gel (i.e., remained closest to the loading wells), whereas those bands with the least base pairs migrated the furthest.

The reproducibility of the molecular typing methods was assessed by fingerprinting 10 cultures of the same isolate of Strep. uberis from 10 different cows (one isolate per cow) that were involved in an experimental infection trial. This same experiment also allowed comparison of the various software options available in the Gelcompar capture software. Our observations suggested that use of the Dice similarity coefficient together with the Ward clustering algorithm exhibited optimal profiles.

The three typing techniques were compared for elucidating the microbial history of 24 isolates obtained from nine cows, some with persistent subclinical mastitis. The primer Ope- 4 was able to differentiate these multiple isolates from cows with recurrent mastitis into 12 strains (Figure 2), the REP primers into 12 strains, and primer P1 into 16 strains.

For primer Ope-4, signature bands were observed at 1613, 1142, and 517 base pairs. Common bands were observed above 1613 at 947, 601, and at 446 bp. Straincharacteristic bands varied between 1142 to 517 bp. For primer P1, the only signature band present was at $1030 \mathrm{bp}$, a common band was observed at $1197 \mathrm{bp}$, and strain-characteristic bands were very hard to define. For REP, signature bands were present at 1976, 884, and $368 \mathrm{bp}$, and common bands were found at 781 to 294 bp. Strain-characteristic bands were more difficult to define, but if present, were between 1976 to $884 \mathrm{bp}$.

In general, individual quarters of the udder were infected primarily by one predominant strain of Strep. uberis. Cows 1215, 719, and possibly cow 698 were the exceptions, possessing isolates with fingerprint patterns that differed from those of the predominant pattern obtained from other isolates. For cow 1215, two isolates (61 from the right front quarter and 62 from the left back quarter) were cultured on August 15. The band pattern of isolate 62 differed from that of isolate 61. However, isolate 83 (cultured from the left front quarter on August 24) and isolate 133 (cultured from the left front quarter on September 24) were identical to isolate 61 . The REP primers recorded an identical result. When primer P1 was used, only isolates 61 and 133 were observed to be identical.

Cow 719 had four isolates cultured on August 16. Two isolates (65 and 67) were identical, whereas the other two isolates (64 and 66) were different by all three typing systems.

Cow 698 had two isolates (27 and 28), which produced different individual patterns from its other isolates only when using primer P1. A value of 96.5\% homology was observed with this primer for these two isolates.

The extent of different fingerprint patterns was then assessed for a further 94 isolates obtained from 94 cows using primer Ope-4. These isolates could be subdivided into 94 strains (i.e., each individual cow possessed its own unique strain) on the basis of their fingerprint pattern. There appeared to be no relationship between strains in individual herds compared with those iso- 

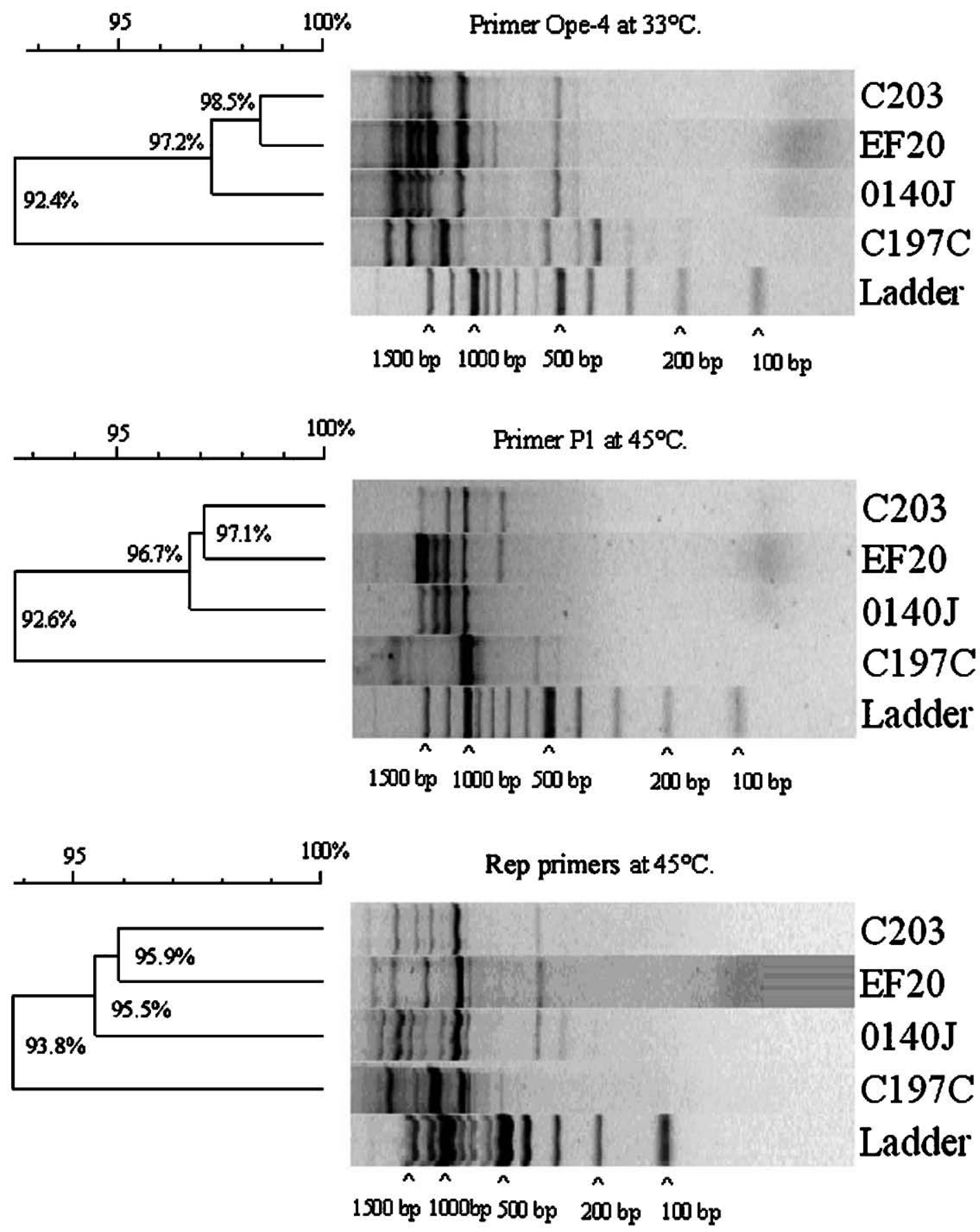

Figure 1. Fingerprints of four reference strains obtained from United Kingdom indicating divergence among them.

lates from different herds. The percentage similarity ranged from 84.1 to $98.5 \%$. A similar result was also recorded using the REP primers (i.e., each individual cow possessed its own unique strain). The percentage similarity for these primers ranged from 81.5 to $98.5 \%$ (data not shown).

\section{DISCUSSION}

Of the three typing systems compared in this report, Ope-4 and REP were the most robust in relation to typeability, i.e., the ability to obtain unambiguous positive results for each isolate. Primer P1 suffered from 


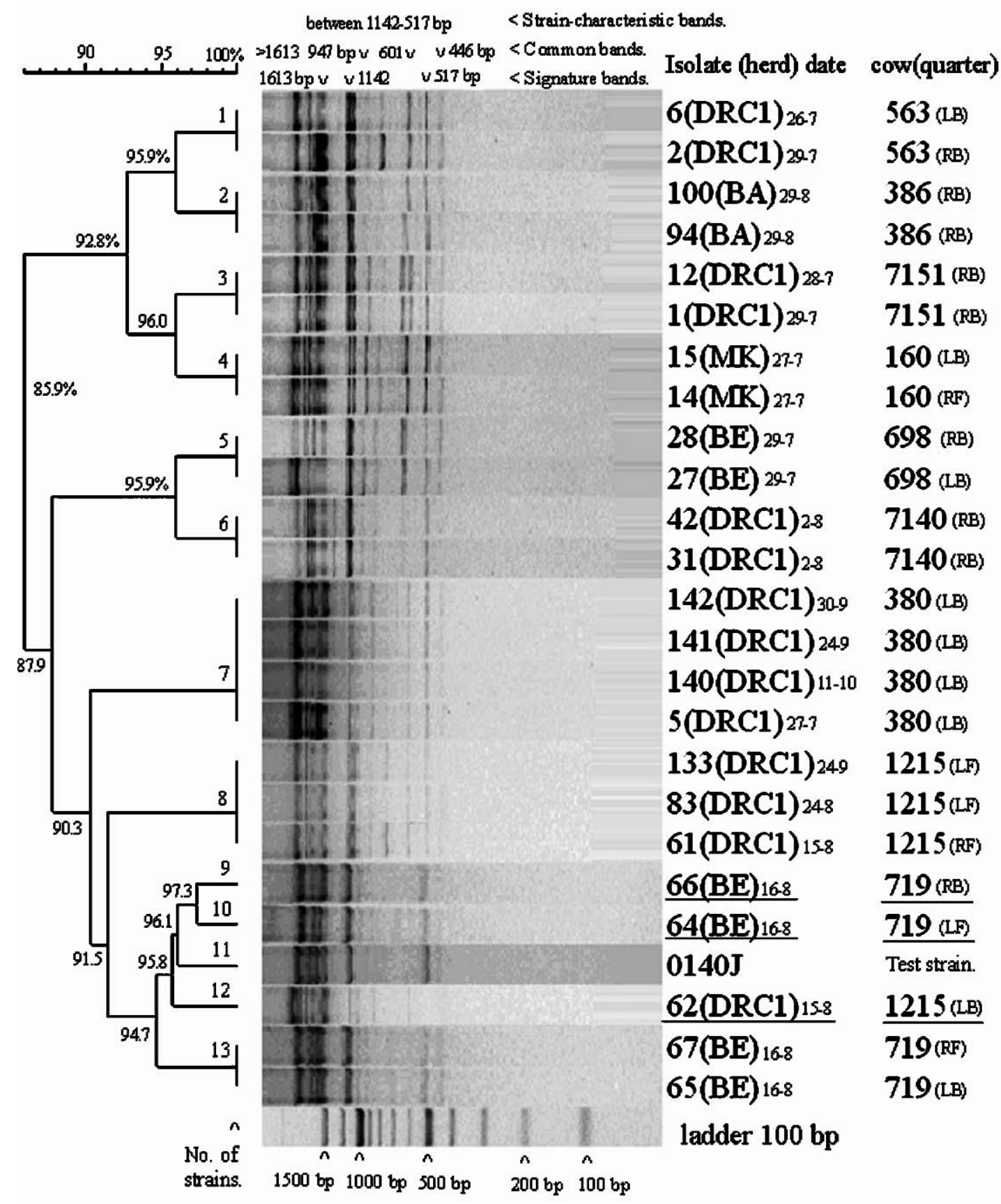

Figure 2. GelCompar software analysis of 24 multiple isolates of Streptococcus uberis from nine cows, some with persistent subclinical mastitis, using primer Ope-4. Degree of homology was calculated by DICE comparisons. WARD clustering algorithm calculated correlation coefficients. Molecular size of bands are indicated at the bottom (100-bp ladders). Underlined strains differed from the fingerprint patterns of the other isolates.

the disadvantage of occasionally producing fingerprints with low numbers of bands, which made differentiation of isolates difficult.

RAPD typing relies on nonstringent reaction conditions for the amplification of arbitrary target sites (Olive and Bean, 1999). Associated with the stringent reac- tion conditions is the difficulty in achieving high pattern repeatability (Gallego et al., 1997). Amplification fragments obtained can be significantly influenced by various factors such as the concentration of reaction mixture components, the source of the DNA polymerase, the thermal cycling program, the brand and model of 
thermal cycler, and the concentration of target DNA used (Gallego and Martinez, 1997). We standardized these conditions in our fingerprinting method to yield constant and reproducible results.

REP typing uses a set of two directed consensus primers to amplify the DNA between repetitive elements that are dispersed in the bacterial genome. Distinct patterns of DNA fragments are generated as a consequence of these repetitive elements adopting different orientations in the bacterial chromosome and the various distances between such elements (Versalovic et al., 1991).

Both RAPD (using primer Ope-4) and REP typing systems investigated in this study demonstrated acceptable reproducibility and discriminatory power. Their application in elucidating the microbal history of cows with persistent infection demonstrated that some cows may be coinfected with more than one strain of Strep. uberis and may become persistently infected (cow 1215).

Bands observed using Ope-4 typing in our study differed from those previously published (Gillespie et al., 1997; Gillespie et al., 1998). Our results confirmed the presence of the 1100,640 , and $450 \mathrm{bp}$ fragments reported previously (Gillespie et al., 1998). We did not observe bands at $300 \mathrm{bp}$ described as a characteristic feature of Strep. uberis isolates from New Zealand. Variation in band size between Strep. uberis strains was seen in fragments sizes of $713,830,940,1300$, and $1500 \mathrm{bp}$. In addition, we observed common bands $>1613$ base pairs. It is possible that these differences in band pattern may have been due to the higher quantity of DNA template used in our studies, or to the different cycle condition and/or the PCR cycler used.

When both Ope-4 and REP typing were applied to 94 isolates of Strep. uberis obtained from another 94 cows, each isolate had a unique banding pattern. This observation is consistent with previous reports obtained by PFGE (Baseggio et al., 1997; Wang et al., 1999; Douglas et al., 2000). The high DNA heterogeneity of Strep. uberis has been previously suggested to be consistent with an environmental reservoir of infections (Wang et al., 1999). Where multiple isolates from individual cows were observed to possess identical fingerprint patterns, there was also supporting epidemiological evidence. Together these results virtually exclude any direct cowto-cow transmission of Strep. uberis.
In conclusion, RAPD typing using Ope- 4 and REP typing systems display advantages of simplicity and low cost (\$11.00 per reaction, Olive and Bean, 1999) in the typing of isolates of Strep. uberis.

\section{REFERENCES}

Baseggio, N., P. D. Mansell, J. W. Browning, and G. F. Browning. 1997. Strain differentiation of isolates of streptococci from bovine mastitis by pulsed-field gel electrophoresis. Mol. Cell. Probes 11:349-354.

Brookbanks, E. O. 1966. A report on surveys on the incidence of mastitis infection in New Zealand dairy herds. N.Z. Vet. J. 14:62-70.

Douglas, V. L., S. G. Fenwick, D. U. Pfeiffer, N. B. Williamson, and C. W. Holmes. 2000. Genomic typing of Streptococcus uberis isolates from cases of mastitis, in New Zealand dairy cows, using pulsedfield gel electrophoresis. Vet. Microbiol. 75:27-41.

Forsman, P., A. Tilsala-Timisjarvi, and T. Alatossava. 1997. Identification of staphylococcal and streptococcal cases of bovine mastitis using 16S-23S rRNA spacer regions. Microbiology 143:34913500 .

Gallego, F. J., and I. Martinez. 1997. Method to improve reliability of random-amplified polymorphic DNA markers. BioTechniques. 23:663-664.

GelCompar Reference Manual: Version 4.1 Edition. 1998. Applied Maths., Kortijk, Belgium.

Gillespie, B. E., B. M. Jayarao, and S. P. Oliver. 1997. Identification of Streptococcus species by randomly amplified polymorphic deoxyribonucleic acid fingerprinting. J. Dairy Sci. 80:471-476.

Gillespie, B. E., B. M. Jayarao, J. W. Pankey, and S. P. Oliver. 1998. Subtyping of Streptococcus dysgalactiae and Streptococcus uberis isloated from bovine mammary secretions by DNA fingerprinting. J. Vet. Med. 45:585-593.

Hill, A. W., and J. A. Leigh. 1989. DNA fingerprinting of Streptococcus uberis: a useful tool for epidemiology of bovine mastitis. Epidemiol. Infect. 103:165-171.

Holdaway, R. J. 1990. A comparison of methods for the diagnosis of subclinical bovine mastitis within New Zealand dairy herds. Ph.D. Diss., Palmerston North, New Zealand.

McDougall, S. 1998. Efficacy of two antibiotic treatments in curing clinical and subclinical mastitis in lactating dairy cows. N.Z. Vet. J. 46:226-232.

Olive, D. M., and P. Bean. 1999. Principles and applications of methods for DNA-based typing of microbal organisms. J. Clin. Microbiol. 37:1661-1669.

Pankey, J. W., R. M. Baker, A. Twomey, and G. Duirs. 1982. Comparative efficacy of dry-cow treatment regimens against Staphylococcus aureus. N.Z. Vet. J. 30:13-15.

Pankey, J. W., P. B. Pankey, R. M. Barker, J. H. Williamson, and M. W. Woolford. 1996. The prevalence of mastitis in primiparous heifers in 11 Waikato dairy herds. N.Z. Vet. J. 44:41-44.

Versalovic, J., T. Koeuth, and J. R. Lupski. 1991. Distribution of repetitive DNA sequences in eubacteria and application to fingerprinting of bacterial genomes. Nucleic Acids Res. 19:68236831.

Wang, S. M., M. A. Deighton, J. A. Capstick, and N. Gerraty. 1999. Epidemiological typing of bovine streptococci by pulsed-field gel electrophoresis. Epidemiol. Infect. 123:317-324.

Williamson, J. H., M. W. Woolford, and A. M. Day. 1995. The prophylactic effect of a dry-cow antibiotic against Streptococcus uberis. N.Z. Vet. J. 43:228-234. 